\title{
Cultural Heritage Storytelling, Engagement and Management in the Era of Big Data and the Semantic Web
}

\author{
Charalampos A. Dimoulas
}

check for

updates

Citation: Dimoulas, C.A. Cultural Heritage Storytelling, Engagement and Management in the Era of Big Data and the Semantic Web. Sustainability 2022, 14, 812. https:// doi.org/10.3390/su14020812

Received: 19 December 2021

Accepted: 5 January 2022

Published: 12 January 2022

Publisher's Note: MDPI stays neutral with regard to jurisdictional claims in published maps and institutional affiliations.

Copyright: (C) 2022 by the author. Licensee MDPI, Basel, Switzerland. This article is an open access article distributed under the terms and conditions of the Creative Commons Attribution (CC BY) license (https:// creativecommons.org/licenses/by/ $4.0 /)$.
Multidisciplinary Media \& Mediated Communication (M3C) Research Group, Aristotle University of Thessaloniki, 54636 Thessaloniki, Greece; babis@eng.auth.gr; Tel.: +30-2310-994245

Cultural heritage $(\mathrm{CH})$ refers to a highly multidisciplinary research and application field, intending to collect, archive, and disseminate the traditions, monuments/artworks, and overall civilization legacies that have been preserved throughout the years of humankind [1-4]. This effort is considered very important for historical and educational purposes, which can be deployed in schooling and training sessions, science and social/humanistic studies, artistic expression, and everyday entertaining environments [5-8]. Today's digital media landscape offers innumerous ways for expediting the above processes at both ends, i.e., $\mathrm{CH}$ content production and "consumption," taking advantage of the contemporary networking utilities with the associated augmented interaction capabilities [9]. For instance, many museums and other art/cultural organizations invested in the development of featured digital applications with appealing storytelling and their online dissemination to engage the audience in featured $\mathrm{CH}$ projects [10-13]. Likewise, the proliferation of mobile devices and services and the vast expansion of the so-called user-generated content (UGC) fueled the digitization of personal $\mathrm{CH}$ artifacts and their progressive organizations in larger-scale databases [14-19]. A typical example in that direction is the Europeana project, which formed specific media archiving and metadata standardization rules for $\mathrm{CH}$ institutions and sole users to follow [20,21]. At the same time, urgent needs for better documentation and management of $\mathrm{CH}$ documents have emerged, making it difficult for the average user to be part of such large-scale undertakings.

Today, Semantic Web and Big Data technologies promise to facilitate more straightforward data analysis, information classification, semantic conceptualization, and management automation of multimodal content, which could also be applied in the benefit of the sensitive CH sectors [22-26]. Specifically, these automation layers could work as mediated communication and collaboration mechanisms between corporations and individuals to accelerate the proper launching, maintenance, and sustainability of suitable $\mathrm{CH}$ repositories, in favor of all the participants. For instance, many significant personal collections have not yet been detected, captured, fully restored, and documented (e.g., photos, films /movies, other private items, etc.). The development of sophisticated digital crowdsourcing procedures with the necessary technological/interdisciplinary cooperation and support would allow mining, shaping, and making available to the public such unique CH masterpieces [14-18]. Thereafter, suitable engaging audience practices and models are welcomed to enhance the impacts of heritage initiatives, amplifying the environmental, cultural, economic, and social sustainability of human beings [8-13].

The current Special Issue launched with the aim of further enlightening the above areas, inviting researchers to submit original/featured multidisciplinary research works related to heritage crowdsourcing, documentation, management, authoring, storytelling, and dissemination. Audience engagement is considered very important at both sites of the $\mathrm{CH}$ production-consumption chain (i.e., push- and pull-ends). At the same time, sustainability factors are placed at the center of the envisioned analysis. A total of eleven contributions $\left(C_{i}, i=1, \ldots, 11\right)$ were finally published within this Special Issue, enlightening various aspects of contemporary heritage strategies placed in today's ubiquitous society. Table 1 
outlines the scientific focus and contribution of the listed articles, prior to the associated description/presentation of the conducted works and their research outcomes.

Table 1. Contributions by research areas, involved technologies, and proposed solutions.

\begin{tabular}{|c|c|c|}
\hline Contributions & Research Area/Focus & Involved Technologies/Solutions \\
\hline Contribution 1 (C1) & $\begin{array}{c}\text { Modeling and Reconstruction of Cultural } \\
\text { Heritage Sites }\end{array}$ & $\begin{array}{c}\text { 3D reconstruction of cultural heritage landmarks } \\
\text { through Twitter image retrieval }\end{array}$ \\
\hline Contribution 2 (C2) & $\begin{array}{l}\text { Cultural Heritage News Propagation in } \\
\text { Social Media }\end{array}$ & $\begin{array}{l}\text { Semantic analysis by qualitative evaluation of } \\
\text { social media news items }\end{array}$ \\
\hline Contribution 3 (C3) & $\begin{array}{c}\text { Environmental Heritage and Green } \\
\text { Culture Transition }\end{array}$ & $\begin{array}{l}\text { Qualitative content analysis on green hosting } \\
\text { communication services }\end{array}$ \\
\hline Contribution 4 (C4) & $\begin{array}{l}\text { Open-Source Multimedia Tools on } \\
\text { Cultural Heritage }\end{array}$ & $\begin{array}{c}\text { Data-driven analytics towards } \\
\text { software sustainability }\end{array}$ \\
\hline Contribution 5 (C5) & $\begin{array}{l}\text { Audience Engagement on the Interactive } \\
\text { Documentary genre }\end{array}$ & $\begin{array}{l}\text { Cultural heritage sustainability analysis by means } \\
\text { of web metrics and usability criteria }\end{array}$ \\
\hline Contribution 6 (C6) & $\begin{array}{l}\text { Digital Narrative for UNESCO Marine World } \\
\text { Heritage of Outstanding Universal Value }\end{array}$ & $\begin{array}{l}\text { Analyzing digital narrative footprint through } \\
\text { social media (Instagram), by evaluating } \\
\text { sustainability and biocultural values }\end{array}$ \\
\hline Contribution 7 (C7) & $\begin{array}{c}\text { Soundscapes Heritage Capturing, Semantics, } \\
\text { and Reproduction }\end{array}$ & $\begin{array}{l}\text { Mobile Journalism (MoJo) semantic capturing } \\
\text { solutions (deploying Machine/Deep Learning) for } \\
\text { data-driven storytelling }\end{array}$ \\
\hline Contribution 8 (C8) & XR Storytelling in Cultural Heritage & $\begin{array}{l}\text { Requirements engineering study for designing } \\
\text { new XR experiences authoring systems }\end{array}$ \\
\hline Contribution 9 (C9) & $\begin{array}{l}\text { Semantic Analysis of Linguistic Resources to } \\
\text { understand the cultural context of an era, nation, } \\
\text { monument, place, etc., }\end{array}$ & $\begin{array}{l}\text { Study on the literature regarding semantic } \\
\text { indexing, incorporating joint transformer-based } \\
\text { models and text summarization techniques }\end{array}$ \\
\hline Contribution 10 (C10) & $\begin{array}{c}\text { Smart Evolution of Historical Cities, Respecting } \\
\text { Cultural Heritage }\end{array}$ & $\begin{array}{c}\text { Study of innovative solutions to support the } \\
\text { energy transition of historical cities in } \\
\text { heritage contexts }\end{array}$ \\
\hline Contribution 11 (C11) & $\begin{array}{l}\text { Extracting Semantic Relationships in Literary Texts } \\
\text { to Sustain Important Cultural Insights }\end{array}$ & $\begin{array}{l}\text { Deep-learning approach to discover semantic } \\
\text { relationships in literary texts, through the } \\
\text { automation of metadata extraction }\end{array}$ \\
\hline
\end{tabular}

The first paper presents an approach for leveraging the abundance of images posted on social media and specifically Twitter for large-scale 3D reconstruction of cultural heritage landmarks. Doulamis, Voulodimos, Protopapadakis, Doulamis, and Makantasis (2021) elaborated on an automatic solution for tweets' content identification, image retrieval/filtering, and 3D reconstruction. The proposed approach extracts key events from unstructured tweet messages and identifies cultural activities and landmarks. Next, content-based filtering selects a representative portion of cultural images to support fast 3D reconstruction. The presented methods are experimentally evaluated using real-world data to verify the effectiveness of the proposed scheme (Contribution 1).

The second paper focuses on the effective communication of cultural heritage initiatives which, in the era of big data and the intense environment of social media, it is considered of equal or-in some cases-even greater importance than heritage data themselves. Maniou (2021) assesses the role of media and journalists in propagating cultural heritage news through social media platforms and the narratives they tend to create in the digital public sphere. A qualitative approach is employed by the study as a means of examining in-depth specific narratives, their meaning(s) and connotation(s), using semantic analysis (Contribution 2).

The third paper deals with the environmental impact of green hosting services, bringing forward new insights regarding green websites and sustainability. Karyotakis and Antonopoulos (2021) investigate how green hosting websites tend to communicate their green services through a qualitative content analysis approach. Therefore, new perspectives on supporting environmental heritage are highlighted, including the education toward sustainable development and a broader green cultural tradition (Contribution 3). 
The fourth paper focuses on the case of open-source multimedia tools on cultural storytelling. Papamichail and Symeonidis (2021) present data-driven analytics towards evaluating the extent to which software components are maintainable based on the evolution of static analysis metrics that quantify primary source code properties (Contribution 4).

The fifth paper casts light on cultural heritage storytelling in the context of interactive documentary, a hybrid media genre that employs a full range of multimedia tools to document reality, provide sustainability of the production and successful engagement of the audience. Podara, Giomelakis, Nicolaou, Matsiola, and Kotsakis (2021) explore the usability of the interactive documentary genre for the sustainability of cultural heritage, analyzing web metrics from a seven-year database. They conclude that interactivity affordances of this genre enhance the social dimension of cultural storytelling, presenting three main factors that enhance audience engagement (Contribution 5).

The sixth paper addresses sustainability, heritage, management, and communication from UNESCO's Marine World Heritage (MWH) perspective. Kenterelidou and Galatsopoulou (2021) analyze its digital narrative footprint through social media (Instagram), examining whether it is framed with sustainability and biocultural values. The study contributes to setting the ground rules for strengthening marine heritage management and communication in light of the United Nations Sustainable Development Goals (SDGs) and the Ocean Literacy Decade (2021-2030) (Contribution 6).

The seventh paper focuses on the development of an enhanced Mobile Journalism (MoJo) model for soundscape heritage crowdsourcing, data-driven storytelling, and management in the era of big data and the semantic web. Stamatiadou, Thoidis, Vryzas, Vrysis, and Dimoulas (2021) elaborate on previous/baseline MoJo tools, deploying Machine and Deep Learning solutions on sound semantics, driven by a thorough analysis of the audience, the technological framework, and the desired heritage crowdsourcing model. Hence, primary algorithmic backend services are implemented and positively validated, providing convincing proof of concept of the proposed model (Contribution 7).

The eighth paper (Mouzakis et al., 2021) provides a requirements' engineering study for designing new eXtended Reality (XR) experiences authoring systems according to the IEEE830 methodology. The study has reviewed 30 existing authoring environments and proposed 10 candidate scenarios for new tools. Six of them were evaluated by 47 individuals in the fields of media, arts, architecture, and informatics. Evaluation results and comments collected can be helpful in future systems design, democratizing XR-media authoring, including the sensitive areas of intangible culture and heritage storytelling (Contribution 8).

The ninth paper presents a study on semantic indexing of 19th-century Greek literature, incorporating transformer-based models and text summarization techniques in a joint fashion. Dimitriadis, Zapounidou, and Tsoumakas (2021) elaborate on the role of literature on cultural heritage to help people understand the cultural context of an era, a nation, a monument, a place, etc., enabling them to adopt more inclusive and equitable attitudes and behaviors. The proposed language understanding automations can help humans classify literature faster and more consistently (Contribution 9).

The tenth paper focuses on the smart evolution of historical cities, integrating innovative solutions that support the energy transition while respecting cultural heritage. Tsoumanis et al. (2021) carried out a study for the implementation of Building-Integrated Photovoltaics (BIPV) solutions in the Historic Centre of Evora is provided, within the framework of the European project POCITYF (Project H2020). The proposed solutions aim at fulfilling all the guidelines for preserving the historic center and achieving the positivity metrics agreed with the European Commission on the challenging and indispensable path to the decarbonization of European cities (Contribution 10).

The eleventh paper emanates from the fact that a vital part of humanity's cultural heritage resides in its literature, a rich body of interconnected works revealing the history and workings of human civilization across the eras. In this context, Christou and Tsoumakas (2021) implement a deep-learning-based approach to discover semantic relationships in 
literary texts (19th century Greek Literature), thus helping to sustain critical cultural insights and facilitating the analysis, organization, and management of collections through the automation of metadata extraction (Contribution 11).

Based on the provided insights, a holistic data-driven $\mathrm{CH}$ approach is envisioned in Figure 1, depicting a generic strategy for engaging the audience into collecting, preserving, sharing, and managing digital heritage. Among others, the diagram projects the relation and complementarity of the eleven scientific contributions $(\mathrm{Ci})$ to the different model phases. Hence, the research works included in this Special Issue are highly representative, appropriately demonstrating the main processes of the end-to-end chain. Nevertheless, future multidisciplinary research and collaborations are also highlighted and anticipated, augmenting the outcomes and the impact of the current Sustainability volume on Cultural Heritage Storytelling, Engagement and Management in the Era of Big Data and the Semantic Web.

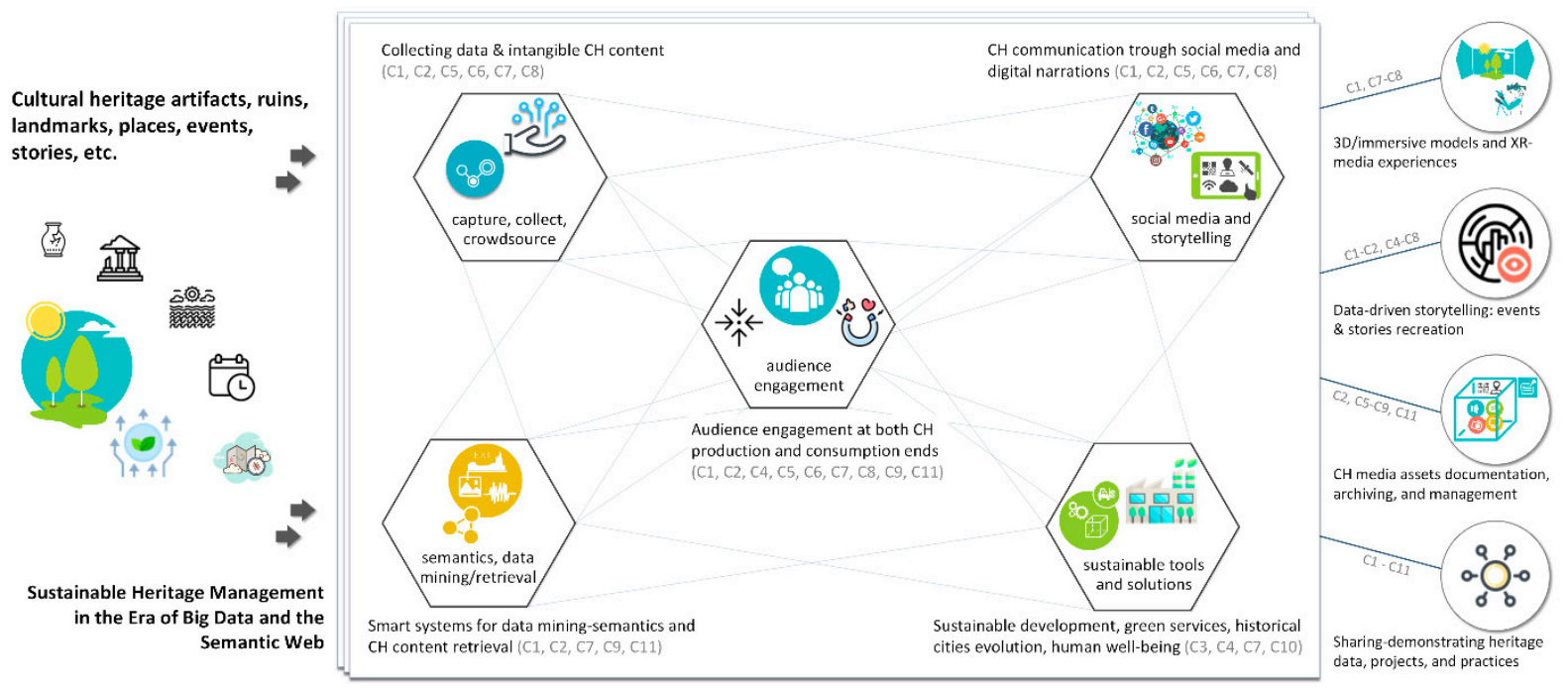

Figure 1. Cultural Heritage Storytelling, Engagement and Management in the Era of Big Data and the Semantic Web: A holistic end-to-end model for engaging the audience into collecting, preserving, retrieving, authoring, sharing, documenting, experiencing, and managing digital heritage.

Table 2 list all the eleven (11) contributions incorporated in this special issue with their associated citations.

Table 2. List of contributions with their associated citations.

Contribution $1(\mathrm{C} 1)$

Doulamis, A.; Voulodimos, A.; Protopapadakis, E.; Doulamis, N.; Makantasis, K. Automatic 3D

Modeling and Reconstruction of Cultural Heritage Sites from Twitter Images. Sustainability 2020, 12, 4223, https:/ / doi.org/10.3390/su12104223.

Maniou, T. Semantic Analysis of Cultural Heritage News Propagation in Social Media: Assessing the

Contribution $2(\mathrm{C} 2)$

Role of Media and Journalists in the Era of Big Data. Sustainability 2021, 13, 341,

https://doi.org/10.3390/su13010341.

Contribution 3 (C3) Karyotakis, M.; Antonopoulos, N. Web Communication: A Content Analysis of Green Hosting Companies. Sustainability 2021, 13, 495, https:/ / doi.org/10.3390/su13020495.

Papamichail, M.; Symeonidis, A. Data-Driven Analytics towards Software Sustainability: The Case of

Contribution $4(\mathrm{C} 4)$

Open-Source Multimedia Tools on Cultural Storytelling. Sustainability 2021, 13, 1079,

https://doi.org/10.3390/su13031079.

Podara, A.; Giomelakis, D.; Nicolaou, C.; Matsiola, M.; Kotsakis, R. Digital Storytelling in Cultural

Contribution 5 (C5) Heritage: Audience Engagement in the Interactive Documentary New Life. Sustainability 2021, 13, 1193, https://doi.org/10.3390/su13031193.

Kenterelidou, C.; Galatsopoulou, F. Sustainable Biocultural Heritage Management and Communication:

Contribution 6 (C6) The Case of Digital Narrative for UNESCO Marine World Heritage of Outstanding Universal Value. Sustainability 2021, 13, 1449, https:/ / doi.org/10.3390/su13031449. 
Table 2. Cont.

Contribution 7 (C7)

Stamatiadou, M.; Thoidis, I.; Vryzas, N.; Vrysis, L.; Dimoulas, C. Semantic Crowdsourcing of Soundscapes Heritage: A Mojo Model for Data-Driven Storytelling. Sustainability 2021, 13, 2714, https://doi.org/10.3390/su13052714.

Contribution $8(\mathrm{C} 8)$ Mouzakis, C.; Ververidis, D.; Girao, L.; Patz, N.; Nikolopoulos, S.; Kompatsiaris, I. Holistic Requirements Analysis for Specifying New Systems for 3D Media Production and Promotion. Sustainability 2021, 13, 8155, https://doi.org/10.3390/su13158155.

Contribution 9 (C9) Dimitriadis, D.; Zapounidou, S.; Tsoumakas, G. Semantic Indexing of 19th-Century Greek Literature Using 21st-Century Linguistic Resources. Sustainability 2021, 13, 8878, https:/ / doi.org/10.3390/su13168878.

Tsoumanis, G.; Formiga, J.; Bilo, N.; Tsarchopoulos, P.; Ioannidis, D.; Tzovaras, D. The Smart Evolution of Contribution 10 (C10) Historical Cities: Integrated Innovative Solutions Supporting the Energy Transition while Respecting Cultural Heritage. Sustainability 2021, 13, 9358, https: / / doi.org/10.3390/su13169358.

Contribution $11(\mathrm{C} 11)$ Christou, D.; Tsoumakas, G. Extracting Semantic Relationships in Greek Literary Texts. Sustainability 2021, 13, 9391, https://doi.org/10.3390/su13169391.

Funding: This research received no external funding.

Institutional Review Board Statement: Not applicable.

Data Availability Statement: Data supporting this article can be found in the listed contributions and their assocciated Data Availability Statements.

Conflicts of Interest: The author declare no conflict of interest.

\section{References}

1. Kontiza, K.; Antoniou, A.; Daif, A.; Reboreda-Morillo, S.; Bassani, M.; González-Soutelo, S.; Lykourentzou, I.; Jones, C.; Padfield, J.; López-Nores, M. On How Technology-Powered Storytelling Can Contribute to Cultural Heritage Sustainability across Multiple Venues-Evidence from the CrossCult H2020 Project. Sustainability 2020, 12, 1666. [CrossRef]

2. Barthel-Bouchier, D. Cultural Heritage and the Challenge of Sustainability; Routledge: London, UK, 2016.

3. Holtorf, C.; Högberg, A. (Eds.) Cultural Heritage and the Future; Routledge: New York, NY, USA, 2020.

4. Dimoulas, C.; Kalliris, G.; Chatzara, E.; Tsipas, N.; Papanikolaou, G. Audiovisual production, restoration-archiving and content management methods to preserve local tradition and folkloric heritage. J. Cult. Herit. 2014, 15, 234-241. [CrossRef]

5. Foster, G.; Saleh, R. The Adaptive Reuse of Cultural Heritage in European Circular City Plans: A Systematic Review. Sustainability 2021, 13, 2889. [CrossRef]

6. Chatzara, E.; Kotsakis, R.; Tsipas, N.; Vrysis, L.; Dimoulas, C. Machine-Assisted Learning in Highly-Interdisciplinary Media Fields: A Multimedia Guide on Modern Art. Educ. Sci. 2019, 9, 198. [CrossRef]

7. Sesana, E.; Gagnon, A.S.; Bertolin, C.; Hughes, J. Adapting cultural heritage to climate change risks: Perspectives of cultural heritage experts in Europe. Geosciences 2018, 8, 305. [CrossRef]

8. Price, N.; Talley, M.K.; Vaccaro, A.M. (Eds.) Historical and Philosophical Issues in the Conservation of Cultural Heritage; Getty Publications: Los Angeles, CA, USA, 2016.

9. Katsaounidou, A.; Dimoulas, C.; Veglis, A. Cross-Media Authentication and Verification: Emerging Research and Opportunities; Chapter 3: The transforming media landscape; IGI Global: Hershey, PA, USA, 2018.

10. Psomadaki, O.; Dimoulas, C.; Kalliris, G.; Paschalidis, G. Digital storytelling and audience engagement in cultural heritage management: A collaborative model based on the Digital City of Thessaloniki. J. Cult. Herit. 2019, 36, 12-22. [CrossRef]

11. Affleck, J.; Kvan, T. A virtual community as the context for discursive interpretation: A role in cultural heritage engagement. Int. J. Herit. Stud. 2008, 14, 268-280. [CrossRef]

12. Waterton, E.; Watson, S. Heritage and Community Engagement: Collaboration or Contestation? Routledge: New York, NY, USA, 2013.

13. Ateca-Amestoy, V.; Villarroya, A.; Wiesand, A.J. Heritage Engagement and Subjective Well-Being in the European Union. Sustainability 2021, 13, 9623. [CrossRef]

14. Hannewijk, B.; Vinella, F.L.; Khan, V.-J.; Lykourentzou, I.; Papangelis, K.; Masthoff, J. Capturing the City's Heritage On-the-Go: Design Requirements for Mobile Crowdsourced Cultural Heritage. Sustainability 2020, 12, 2429. [CrossRef]

15. Vryzas, N.; Sidiropoulos, E.; Vrysis, L.; Avraam, E.; Dimoulas, C.A. A mobile cloud computing collaborative model for the support of on-site content capturing and publishing. J. Media Crit. 2018, 4, 349-364.

16. Dimoulas, C.A.; Symeonidis, A.L. Syncing Shared Multimedia through Audiovisual Bimodal Segmentation. IEEE Multimed. 2015, 22, 26-42. [CrossRef]

17. Vryzas, N.; Sidiropoulos, E.; Vrysis, L.; Avraam, E.; Dimoulas, C. Machine-assisted reporting in the era of Mobile Journalism: The MOJO-mate platform. Strategy Dev. Rev. 2019, 9, 22-43. [CrossRef]

18. Meyer, É.; Grussenmeyer, P.; Perrin, J.P.; Durand, A.; Drap, P. A web information system for the management and the dissemination of Cultural Heritage data. J. Cult. Herit. 2007, 8, 396-411. [CrossRef] 
19. Rodríguez-Gonzálvez, P.; Jiménez Fernández-Palacios, B.; Muñoz-Nieto, Á.L.; Arias-Sanchez, P.; Gonzalez-Aguilera, D. Mobile LiDAR System: New Possibilities for the Documentation and Dissemination of Large Cultural Heritage Sites. Remote Sens. 2017, 9, 189. [CrossRef]

20. Macrì, E.; Cristofaro, C.L. The Digitalisation of Cultural Heritage for Sustainable Development: The Impact of Europeana. In Cultural Initiatives for Sustainable Development: Management, Participation and Entrepreneurship in the Cultural and Creative Sector; Demartini, P., Marchegiani, L., Marchiori, M., Schiuma, G., Eds.; Springer Nature: Cham, Switzerland, 2021.

21. Freire, N.; Voorburg, R.; Cornelissen, R.; de Valk, S.; Meijers, E.; Isaac, A. Aggregation of Linked Data in the Cultural Heritage Domain: A Case Study in the Europeana Network. Information 2019, 10, 252. [CrossRef]

22. Vavliakis, K.N.; Karagiannis, G.T.; Mitkas, P.A. Semantic Web in cultural heritage after 2020. In Proceedings of the 11th International Semantic Web Conference (ISWC), Boston, MA, USA, 11-15 November 2012; pp. 11-15.

23. Noor, S.; Shah, L.; Adil, M.; Gohar, N.; Saman, G.E.; Jamil, S.; Qayum, F. Modeling and representation of built cultural heritage data using semantic web technologies and building information model. Comput. Math. Organ. Theory 2019, 25, 247-270. [CrossRef]

24. Bikakis, A.; Hyvönen, E.; Jean, S.; Markhoff, B.; Mosca, A. (Eds.) Special issue on Semantic Web for Cultural Heritage. Semant. Web 2021, 12, 163-167. [CrossRef]

25. Amato, F.; Moscato, V.; Picariello, A.; Colace, F.; Santo, M.D.; Schreiber, F.A.; Tanca, L. Big data meets digital cultural heritage: Design and implementation of scrabs, a smart context-aware browsing assistant for cultural environments. J. Comput. Cult. Herit. 2017, 10, 1-23. [CrossRef]

26. Nishanbaev, I.; Champion, E.; McMeekin, D.A. A Survey of Geospatial Semantic Web for Cultural Heritage. Heritage 2019, 2, 1471-1498. [CrossRef] 